\title{
Estrecho de Magallanes: viaje, relato y archivo
}

\section{(4) María Jesús Benites}

Invelec/Conicet - IIELA/Universidad Nacional de Tucumán, Argentina

Fecha de recepción: marzo 2019. Fecha de aceptación: junio 2019.

\begin{abstract}
Resumen
La travesía magallánica no solo significó encontrar el paso que unía ambos océanos, sino también logró, por primera vez, circunnavegar el mundo. Partir de un lugar y retornar a él son los movimientos complementarios que transforman este viaje en una hazaña sin precedentes. En la acción de atravesar ese pasaje-mundo (Onetto, 2018) se confirma la redondez de la Tierra, se afianza el conocimiento total sobre ella y la posibilidad de su absoluta e imperialista posesión.
\end{abstract}

Este trabajo propone un recorrido por los relatos que dan cuenta, de manera directa y diferida, de la travesía que inicia en 1519 Magallanes y culmina Elcano en 1522. Está organizado en las tres modulaciones que anticipa el título: viaje, relato y archivo.

\section{Strait of Magellan: travel, narrative and archive}

\begin{abstract}
The Magellanic journey not only meant finding the passage that united both oceans, but also, for the first time, managed to circumnavigate the world. Starting from a place and returning to it are the complementary movements that transform this trip into an unprecedented feat. In the action of crossing that passage-world (Onetto, 2018) the roundness of the Earth is confirmed, total knowledge about it and the possibility of its absolute and imperialist possession are strengthened. This paper proposes a tour of the stories that give a direct and deferred account of the journey that begins in 1519 with Magallanes and culminates with Elcano in 1522. It is organized in the three modulations anticipated by the title: travel, narrative and archive.
\end{abstract}

\section{Resumo}

A viagem de Magalhães não apenas significou encontrar a passagem que unia os dois oceanos, mas também, pela primeira vez, conseguiu circunavegar o mundo.

\section{Palabras clave:}

Relato de viaje Estrecho de Magallanes Siglo XVI

\section{Keywords:}

Travel story Strait of Magellan 16th Century

\section{Palavras chave:}

História de viagem Estreito de Magalhães Século XVI 
Começando de um lugar e retornando a ele, são os movimentos complementares que transformam essa viagem num feito sem precedentes. $\mathrm{Na}$ ação de atravessar essa passagem-mundo (Onetto, 2018), a redondeza da Terra é confirmada, o conhecimento total sobre ela e a possibilidade de sua posse absoluta e imperialista são fortalecidos. Este artigo propõe um tour pelas histórias que fornecem um relato direto e diferido da viagem que começa em 1519 Magallanes e culmina em Elcano em 1522. Está organizado nas três modulações previstas pelo título: viagem, história e arquivo.

\section{El viaje: abrazando el Nuevo Mundo}

En 1584 el navegante Pedro Sarmiento de Gamboa anhela, en clave utópica, colonizar las costas del Estrecho de Magallanes. Sesenta años habían transcurrido entre la quimera sarmientina y la travesía que descubriera ese paso y que precipitara sucesivas expediciones y un corpus de relatos de viajes que agrupo bajo la expresión escrituras imperiales de los confines, enunciado que involucra la idea de un espacio lejano y próximo, un espacio que es recorrido y un viaje que se presupone como acto de apropiación. Digo presupone porque los confines remiten al límite, redefinen el finibusterre, esa línea imaginaria que separa, divide y distingue un territorio de otro. Pero el término también se proyecta en la condición de estar desterrado. Imposible no asociar confín con el punto donde todo culmina, con ese proceso de representación de nuestro extremo sur casi como un espacio de confinamiento y castigo. La cárcel del fin del mundo es más que una indulgente metáfora, es la expresión categórica de la construcción de esa geografía como inhóspita, distante, ajena.

La travesía magallánica no sólo significó encontrar el paso que unía ambos océanos, esa herida que une y separa, sino que logró, por primera vez, circunnavegar el mundo. Partir de un lugar y retornar a él son los movimientos complementarios que transforman este viaje en una hazaña sin precedentes. En la acción de atravesar el pasaje-mundo como define Mauricio Onetto (2018) al estrecho, se confirma la redondez de la Tierra, se afianza el conocimiento total sobre ella y la posibilidad de su absoluta e imperialista posesión. El propio Elcano, en la carta que dirige a Carlos $\mathrm{V}$ cuando regresa a bordo de la Victoria, la única de las cinco naos que sobrevive, es consciente del impacto de la hazaña: y más sabrá Vuestra Majestad que aquello que más debemos estimar y tener es que hemos descubierto y dado la vuelta a toda la redondez del mundo, que yendo para el Occidente hayamos regresado por el Oriente. 6 de septiembre de 1522. (Onetto, 2018: 12).

Me detengo en esta frase de Séneca, el Viejo, que tiene como interlocutor ficticio a Alejandro Magno:

Dicen que en el océano se encuentran tierras fértiles y que allende el océano hay otras costas, otro mundo; dicen que la naturaleza no tiene fin, sino que brota siempre renovada allí donde parece terminarse. Son suposiciones fáciles de hacer dado que no se puede surcar el océano [...]. El mar permanentemente inmóvil y cual masa inerte de naturaleza parece desvanecerse en sus confines. Hay formas desconocidas, espantosas, monstruos enormes incluso para el océano a los cuales alimenta esa vasta inmensidad; la luz queda vedada por la intensa niebla y el día se ve interrumpido por las tinieblas, el mar mismo es pesado y fijo, y no hay estrellas o son desconocidas. El mundo es tuyo Alejandro. Al final de todo, el océano; al final del océano, nada. (Séneca, 2005)

Quizás se podría pensar que esta cita del siglo I antes de Cristo es anacrónica en su representación desbordada del mar y los peligros que acechan a quien osa surcarlo, 
no obstante, en el profuso estudio cartográfico que propone Chet Van Duzer (2018) se pueden apreciar la recurrencia de monstruos marinos asolando el océano en las representaciones medievales y renacentistas, como los mapas Munster o de Oleus Magnus.

En el siglo XVI atravesar el mar suponía enfrentarse a un territorio tenebrosum, inestable y aterrador. Jean Delumeau afirma que el océano era "por excelencia el lugar del miedo" donde no existía "entre la vida y la muerte más que el espesor de una tabla de madera que solo tiene tres o cuatro dedos de anchura" (1978: 37). En este contexto la empresa magallánica redefine el concepto de límites no sólo geográficos sino también humanos y náuticos. El navegante pasa a ser el sujeto que explica, atravesado por su experiencia vital, el mundo.

Poco más de veinte años separan esta primera circunnavegación del orbe, del portulano trazado por Juan de la Cosa, ${ }^{1}$ primera representación cartográfica del continente donde las líneas conectan dos universos: uno profusamente ilustrado y otro que aún no ha terminado de definirse. Hacia el sur, el trazado se pierde y el último lugar geográficamente identificable es el de las costas de Brasil. El recorrido culmina en ese punto, matizado por un color verde penetrante y auspicioso. Si existiera un modo verbal que tradujera el trazado, tendría que ser el potencial, porque lo que este mapa sugiere es lo que podría ser, la prefiguración de lo posible. En las líneas de fuga del ángulo izquierdo del portulano, el espacio ausente del mapa es al que se aventura Magallanes el 20 de septiembre de 1519 cuando parte desde Sanlúcar de Barrameda con una flota de cinco navíos. Basado en conocimientos geográficos que hacían presuponer que los continentes no eran sino islas gigantescas, le pareció acertado navegar hacia el sur, hasta que apareciera el paso que uniera ambos océanos y abriera una nueva ruta hacia la especiería. La tripulación estaba constituida por más de doscientos cincuenta hombres de los cuales retornarán solo dieciocho.

Como explica Guillermo Giucci (2014), el proyecto de Magallanes, junto con su socio Ruy Falero, era arribar por el oeste a las islas Molucas sin atravesar dominios lusitanos. A cambio, pedían el monopolio por diez años y la gobernación de las tierras descubiertas por tiempo ilimitado, peticiones desmedidas que generaron diversas negociaciones y el disgusto del rey Emanuel de Portugal quien trató de impedir que Magallanes embarcase. ${ }^{2}$

Peter Sloterdijk habla de la "huella de la revolución magallánica de la imagen de mundo" (2004: 729), equiparando la importancia de la travesía con la revolución copernicana. Si con Copérnico la Tierra gira en torno del Sol, con Fernando de Magallanes, el comercio y el dinero son los que ponen a girar la Tierra en torno de ellos e impulsan los navíos. Serge Gruzinski refuerza esta idea: "La revolución magallánica atañe inmediatamente a marineros, comerciantes, financieros, príncipes y cronistas; hace del mar y de la movilidad de los hombres y de los capitales el motor de todas las circulaciones y todos los enclaves. No existe mundialización sin revolución magallánica [...]" (Gruzinski, 2018: 282)".

Distintos asientos de la Instrucción Real encargada por Carlos $\mathrm{V}$ y redactada por el Consejo de Indias ${ }^{3}$ se centran en ese movimiento económico y comercial y en la demarcación de futuros puertos y entradas.

E por cuanto no sabemos el tiempo que vos terneis en este descubrimiento, é porque algunas de las personas que van en la dicha Armada les parecerá ser mucho el tiempo que habéis andado sin hallar nada, notificaldes á todos juntamente, é á cada uno por sí, poniéndoles grandes penas, que mientras el mantenimiento tovieron en abundancia, ninguno sea osado á hablarni hable en el dicho viaje ni descubrimiento, ${ }^{4}$ estar mucho tiempo ni poco, sino que dejen hacer á los que llevan cargo dél; é lo mismo vos
1. Juan de la Cosa era un marino cántabro que acompañó a Cristóbal Colón, como maestre de nao, en sus dos primeros viajes. En total realizó siete viajes al Nuevo Mundo hasta 1511, año de su muerte en Cartagena de Indias. El único autor contemporáneo a la confección de la carta que la cita es Pedro Mártir de Anglería en sus Décadas del Nuevo Mundo (Década II, cap. X).

2. Si bien no era infrecuente que se contrataran extranjeros para comandar las expediciones, estos quedaban obligados a compartir el mando con oficiales españoles. 3. En el Archivo General de Indias (de ahora en más A.G.I.) se conserva en el Patronato 34, Rama 8, una copia de la extensa Instrucción dada por Carlos V a Fernando de Magallanes escrita en doce folios de ambos lados y uno de una sola cara. El documento está firmado en Barcelona el 8 de mayo de 1519. La letra es cortesana procesal. Hay un detalle llamativo en el manuscrito y es el de la amplitud de los márgenes que ha dejado el redactor. Las instrucciones reales tienen como principio organizativo la necesidad de transmitir directivas y órdenes a quienes inician una travesía. Estos documentos no predeterminan pero tampoco excluyen un ejercicio posterior de escritura, ya que requieren actos como los de observar, describir y medir. Las instrucciones se presentan como un instrumento con múltiples funciones: por un lado, es un mecanismo que permite "ordenar" la observación; por el otro, supone un ejercicio coercitivo de cumplimiento que refuerza y hace visible, una vez más, el respeto a la jerarquía que subyace en el texto y el efecto de poder que crea en aquellos a quienes se dirige. 4. El destacado es mío. 
5. Es decir, a "la narración o informe que se hace de alguna cosa que sucedió" (Covarrubias Horozco, 1943).

6. Defino la categoría de relatos de viaje como un texto que se articula sobre el trazado y el recorrido de un itinerario, trazado que se ordena a partir de una cronología que da cuenta del desarrollo del viaje y del tiempo transcurridos; forman parte de la material textual y son componentes capitales las descripciones geográficas; se evidencia la incorporación de digresiones asociadas a elementos o factores maravillosos; la presencia de un narrador que refiere los sucesos a partir de la propia experiencia, o si es diferida da cuenta de sus informantes. Todos estos aspectos están atravesados, aunque no de modo excluyente, por la dimensión espacial puesto que tanto describir y narrar son acciones complementarias en el relato de viaje: la primera funciona como un acto de fijación (de Certeau, 2000), fundadora de los espacios. La narración, en cambio, se centra en la experiencia del sujeto que los atraviesa ya sea a pie o embarcado. Ver Benites, María Jesús: “Los derroteros teóricos de una categoría heterogénea: Los relatos de viajes al Nuevo Mundo (siglo XVI)". En Moderna Sprak. Vol. 107, No. 1, 2013, pp. 31-38 y “'Vigilias, fatigas y peregrinaciones': viaje, relato y desamparo en los confines del imperio". En Telar 11-12. IIELA Tucumán, 2014, pp. 80-93. encomendamos á vosotros éá ellos, que no os dé pena el mucho andar por el mar, sino que trabajéis por descubrir la mas tierra que pudiéredes, porque haciéndolo, no puede ser sino que se descubra mucha costa, de que de vosotros é dellos seamos servidos, y el armazón reciba mucho provecho. (Fernández de Navarrete, 1837, T. IV: 142)

El mar como espacio del miedo, como esa nada, se resignifica, entonces, en lugar de tránsito; se abandona la actitud conjetural con respecto a las distancias, y lo que se descubre, más que un pasaje entre océanos, es un océano que une, con su diversidad de corrientes y nombres, el mundo.

\section{Los relatos: entre la injusticia y la sinrazón}

Desde el pedido inicial de los reyes católicos para que el Almirante trajera "entera relación" de los avatares de su empresa, se anticipa la necesidad de transmitir las noticias de las nuevas posesiones y sistematizar los mecanismos para administrarlas y someterlas al dominio imperial. El primer vínculo escrito que se establece entre el Nuevo y el Viejo Mundo es el de una narración que tematiza la travesía que los une. Es el acto mismo del viaje, de su transcurrir y sus modos de realización lo que es traducido en palabras para el lector "oficial" pero también, como veremos, para el curioso.

Si bien el corpus que recorro se adscribe, de manera general, al tipo discursivo de "relación", he optado por agruparlo bajo la categoría de relato de viaje, ${ }^{6}$ cuya materia y organización disputa límites, genera tensiones y pone en cuestionamiento su pertenencia, cual desposeído retórico, al discurso historiográfico, depositario en el siglo XVI de los documentos que refieren lo visto y lo vivido bajo la incuestionable tutela de lo "verdadero".

Los textos que refieren, tanto de manera directa como diferida pero contemporánea, la travesía magallánica son Primer viaje alrededor del mundo de Antonio de Pigafetta, la carta relatoria de Maximiliano de Transilvano, secretario de Carlos V, el libro VII de la Década $V$ dedicada al sumo pontífice Adriano VI que redacta el cronista oficial Pedro Mártir de Anglería, el "Derrotero"

\section{de Francisco Albo y el relato del piloto de la nao Trinidad Ginés de Mafra.}

El corpus establece una dinámica interna particular. Las escrituras de Pigafetta, Albo y Mafra están atravesadas por la experiencia directa, Anglería y Transilvano, en tanto, reciben la información de Elcano y otros tripulantes apenas arriban a España. Ambos textos junto con el de Pigafetta transcienden la letra impresa en tanto que los de Albo y Mafra permanecen inéditos hasta el siglo XIX y XX respectivamente.

El criterio que los agrupa es que son escrituras fundantes de un espacio hasta ese momento ignoto y dan cuenta de las vicisitudes del viaje con sus traiciones, deslumbramiento y naufragios, en ellos redundan la violencia y la descripción del estropicio tanto de los cuerpos como de las naves, aspectos que se entraman en dos gestos: el de describir que guía las secuencias más útiles a los fines colonizadores, y el de narrar, más valioso para nuestro análisis puesto que refleja los vínculos entre quien escribe y la geografía que recorre.

Excede los alcances de este artículo afrontar una lectura integral de cada uno de los textos por esto he optado por acompañar el movimiento de los barcos y detenerme, como intersticio de lectura, en las costas patagónicas, momento en el que Magallanes 
decide, de manera arbitraria, pasar el invierno en Bahía de San Julián. En ese territorio permanecen, enclaustrados en los barcos, los meses previos al ingreso al estrecho y al descubrimiento del océano Pacífico. El estado de hacinamiento, las enfermedades y las desavenencias surgidas durante la navegación eclosionan en aquella costa, la invernada será fatídica, no solo por la destemplanza de la tierra sino también por la sucesión de asesinatos, deserciones y hambruna.

Vuelvo al asiento de la instrucción y a los modos en que se impone el silencio, a esa prohibición de hablar sobre el propio transcurrir porque potencia la figura del barco, elemento que hace años me interpela como sinécdoque del viaje y las relaciones humanas ${ }^{7}$. En una tierra estéril, la embarcación es primordial, es el único referente que permite construir en la mente del viajero la idea del retorno. Descender de los barcos supone abandonar el resguardo, es abandonar la condición de "viajero" para transformarse en desamparado. Isabel Soler concibe "el mar como la falta de sostén, es la ruta sin camino, donde la supremacía de la naturaleza fragiliza al ser que se adentra en él porque irremediablemente está sometido a su arbitrio", (2003: 97). El barco es el espacio de la contención en ese universo inconmensurable que es el océano. La lectura del documento real ${ }^{8}$ refleja de modo prosopopéyico ese rol fundamental de la flota pensada como un colectivo.

La dicha nao del farol quisiere saber si van todas las naos á vista della, harán un fuego, é todas las otras responderán con otros sendos, porque vos sepáis que van todas, é cuando la nao del farol quisiere virar en otro borde hará dos fuegos, é responda con otros dos cada navio, é después que vos respondieren todos virareis, é lo mismo harán ellos: é porque vos sigan haréis un fuego como de antes: é cuando quisieredes quitar alguna boneta haréis tres fuegos, y ellos responderán con otros tres: é para amainar haréis cuatro fuegos, é respondiendo con otros cuatro amainareis todos: é si, lo que Dios no quiera, alguna de las dichas naos se desaparejase, la dicha nao hará muchos fuegos, porque todos los otros navíos le acudan é vayan (Fernández de Navarrete, 1837, T. IV: 132 ).

El mar es espacio de circulación pero también es un desierto, riguroso y hostil. El límite espacial que imponen las naos al rumor y al malestar estalla ante la pobreza de las costas a las que arriban.

El texto más conocido es el de Antonio Pigafetta, ${ }^{9}$ que no escribe obligado por un mandato; su obra es el resultado de un libre ejercicio de la observación que le permite seguir un criterio selectivo de los hechos. Desde las motivaciones que lo impulsan a emprender la travesía manifiesta un afán de conocimiento. En esta lógica de silenciamientos, su escritura aporta otro dato relevante: "su proyecto no lo comunicó [Magallanes] en detalle a ninguno de sus compañeros de expedición, para evitar que intentasen disuadirle de su propósito de seguir una ruta hasta entonces desconocida, a través de mares tempestuosos en que habrían de arrostrarse peligros sin cuento" (Pigafetta, 2004: 33).

Pigafetta no da casi cuenta de esos peligros durante la estancia en San Julián: es escueto, no manifiesta asombro ni juzga, quizás por su propia condición de extranjero, la conducta de Magallanes. Hay una desdramatización de los acontecimientos y el relato es controlado.

Al poco tiempo de estar en el puerto, los Capitanes y otros oficiales de la armada urdieron un complot para asesinar a Magallanes, siendo los principales Juan de Cartagena, veedor de la escuadra; Luis de Mendoza, tesorero; Antonio Cocca, contador y Gaspar Casada [por Quesada], capitán de la nave Concepción. Descubierto que se hubo la trama, fueron muertos y descuartizados los dos primeros. El Capitán
7. Insisto en la presencia textual de las embarcaciones como un elemento central puesto que el navío se piensa y se construye en la mente de los viajeros como un albergue, un refugio que brinda la protección necesaria ante la adversidad y los embates a los que eran sometidos los navíos durante las tormentas o tempestades. 8. En el A. G. I. se conserva, Patronato 34 - Rama 8, una copia de la extensa instrucción dada por Carlos $\checkmark$ a Fernando de Magallanes escrita en doce folios de ambos lados y uno de una sola cara. El documento está firmado en Barcelona el 8 de mayo de 1519. La letra es cortesana procesal. La instrucción entregada al "Gobernador del Maluco" se ubica en el momento inicial del proceso de sistematización de los datos que se desean obtener sobre el Nuevo Mundo, aún no se especifica una obligatoriedad ni se establecen los elementos centrales que deben guiar el ejercicio de la observación.

9. Tres copias en francés - dos en la Biblioteca Nacional de París y la otra en una colección particular-y un manuscrito en italiano se conservan del texto primigenio. Se cree que estos cuatro textos son copia de un original extraviado. Las biografías explicitan que Pigafetta era un estudioso de la geografía, la astronomía y un conocedor de los fenómenos celestes. 
10. Los seres que describe Pigafetta no distan, por ejemplo, de las imágenes que crea François Rabelais en 1532 para describir a sus memorables Gargantúa y Pantagruel.

11. Sofía Carrizo Rueda (1997) define a este tipo de relato como aquél en el que predomina la función descriptiva asociada a la escritura como un espectáculo. La confección del material narrativo se organiza alrededor de núcleos que corresponden a un principio de selección y jerarquización y que responden, y esto es destacable, a expectativas y tensiones profundas de la sociedad a la que se dirigen. 12. Se ha discutido mucho acerca del origen del término patagón. En Historia general y natural de las Indias (1535-1557), Gonzalo Fernández de Oviedo, señala que el nombre se debe al gran tamaño de sus pies. Con esta acepción figura en el Diccionario de Autoridades: “Lo mismo que patón.

(continúa en página 29)

13. La cita pertenece a la edición de las Décadas realizada en Madrid, Polifemo, 1989, con Introducción de Ramón Alba y revisión de Julio Martínez Mesanza. Esta edición reproduce la traducción castellana que Joaquín Torres Asensio publicara en 1892.

14. La cursiva me pertenece. Cuando Pedro Mártir de Anglería describe las acciones de Magallanes suele usar verbos latinos que ponen de manifiesto la crudeza de sus decisiones. En este fragmento, donde el traductor señala "Magallanes se ensañó", el humanista utiliza el verbo saevio que está emparentado etimológicamente con el sustantivo latino vis (violencia). Agradezco esta observación al Dr. Carlos Castilla (UNT). general perdonó a Gaspar de Quesada; pero habiendo reincidido en su siniestro propósito, le envió a Tierra (en Patagonia), con un cura, su cómplice, dejándolos allí abandonados, no dando muerte a aquel traidor por respeto a haber sido nombrado por el emperador para el cargo que ejercía. (Pigafetta, 2004: 46).

En todo relato que refiere un recorrido, existe una fragmentación del paisaje, imágenes secuenciadas del mundo observado. Para Pigafetta el mundo que se revela ante sus ojos es el escenario donde se activa el factor maravilloso.

Durante dos meses no vimos alma viviente por aquella tierra; un día apareció de improviso en la playa un hombre de estatura gigantesca casi desnudo, que, bailando y cantando, se echaba arena en la cabeza. Dispuso Magallanes que fuese un hombre a tierra con encargo de imitar al salvaje en sus movimientos, en señal de paz. Comprendió aquél que no íbamos en actitud hostil, y se dejó conducir a una isla vecina, donde estaba nuestro jefe con varios de los nuestros [...]. Era tan alto aquel hombre que le llegábamos a la cintura, siendo en lo demás muy proporcionado (Pigafetta, 2004: 41).

La presencia del hombre es asociada a la de un gigante, imagen del cuerpo en la que se conjugan los excesos y las deformidades. ${ }^{10}$ En Primer Viaje la indefinición del espacio geográfico motiva el surgimiento del elemento maravilloso y lo desbordante que se contraponen a una naturaleza marcada por la carencia. Pigafetta se ampara en el modelo textual de los relatos medievales donde lo asombroso funciona como un componente primordial del discurso porque responde, y luego lo retomaré, a las expectativas de los lectores a los que se proyecta (Sofía Carrizo Rueda: 1997). ${ }^{11} \mathrm{La}$ letra captura la imagen del gigante e inicia un proceso de apropiación tanto del territorio-región, bajo un nombre ajeno: la Patagonia ${ }^{12}$ como de los cuerpos. El autor reitera el afán de llevar uno de esos "gigantes" para exhibirlo al rey: el cuerpo de un hombre pensado como un elemento más de la cámara de los tesoros.

Pedro Mártir refiere en su Década los sucesos de San Julián para ahondar en una cuestión clave: el enfrentamiento político entre españoles y portugueses, obstáculo inicial que vaticinaba sucesos adversos. Está documentado por Martín Fernández de Navarrete (1837) el modo en el que los oficiales de la Casa de Contratación, siempre manifestaron "aversión" (T. IV, p. XLII) por Magallanes, y pusieron, hasta último momento, reparos para entorpecer el apresto de la Armada con la intención inconfesada de frustrar la travesía.

De todos modos, Anglería describe las circunstancias de quienes deben pasar más de "cuatro meses bajo tugurios y chozas" (Anglería, 1989: 353). Las circunstancias apremiantes que rodean a Magallanes y sus hombres "detenidos por el frío y encerrados

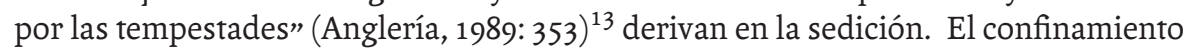
del barco se resignifica en las costas. Pedro Mártir no habla de los asesinatos, pero sí se detiene en el destierro de Juan de Cartagena:

Aquí el portugués Magallanes se ensaño ${ }^{14}$ con cierto varón llamado Juan Cartagena, familiar del obispo de Burgos, que con real nombramiento había sido señalado por colega de Magallanes y segundo jefe de la Armada. A éste y a un sacerdote, en ocasión de asechanzas que urdían para matarle, les dejó en tierra con una alforja de galletas y una espada para cada uno; habría querido castigar con pena de la vida sus intentos, si acaso pensaron en matarle; pero no se atrevió temiendo al odio de los castellanos, que ya lo tenían. Este asunto y otros a éste semejantes, lo cuentan varios de varias maneras: unos dicen que Magallanes tuvo razón para hacer lo que hizo; otros se lo afean, y atribuyen aquellas ejecuciones a la antigua animosidad general entre castellanos y portugueses (Anglería, 1989: 353). 
En la carta de Transilvano ${ }^{15}$, quien, si bien al igual que Anglería no participa de manera directa de los sucesos que informa, los episodios de San Julián ocupan la mitad de los fragmentos que estructuran la obra. El secretario real escribe desde una primera persona que informa las vicisitudes del viaje en tono laudatorio para exaltar la "admirable" travesía de quienes regresaron de "aquel mundo extraño" (15).

La de Transilvano es más que una carta personal, es la narración de una aventura sin precedentes que explicita su compromiso con la verdad de lo narrado. Entendido en estos términos, el texto puede ser analizado como un relato de viaje que surge de la propia necesidad de referir las peripecias para un lector determinado, pero también para otros potenciales ${ }^{16}$ puesto que ha procurado, con mucha diligencia, informarse de la verdad de todo ello. ${ }^{17}$

En el desarrollo narrativo, la costa patagónica es percibida como hostil e intimidante y la letra exterioriza el miedo que se acrecienta por las privaciones de refugio, de alimento y por la sensación de estatismo de las naves. Son escenas de lo que denomino "narrativa del desamparo" ${ }^{18}$ categoría que entrecruza polifónicamente la decepción ante el fracaso, la necesidad de cumplir con el mandato, la ambición por alcanzar un objetivo fabuloso y ese penoso deambular. ${ }^{19}$

El énfasis de la escritura está puesto en las tensiones que vinculan cuerpo y espacio y que asocian el hambre y el frío con la idea del confinamiento y la condición del destierro. Es que el relato de viaje es también una escritura corpórea (Margo Glantz, 1992). Elijo esta cita de Transilvano con resonancias de la frase de Séneca, el viejo, porque refuerza el tono épico de un viaje con retorno.

[...] rogaron al capitán Magallanes [...] que se volviese atrás donde no hiciese tan áspero invierno porque no sufriesen tanta fatiga, pues veía que mientras más adelante pasaban, más insoportable frío les hacía, sin esperanza de hallar fin a aquella tierra firme, ni el pasaje que para el otro mar buscaban, y que pereciendo, como muchos de ellos perecían, de hambre y frío, era imposible poder durar mucha tiempo [...] y que pues la intención y voluntad del emperador no había sido que ellos tentasen obstinadamente lo que veían a la clara que les obstaba y contradecía la natura y las otras dificultades, le rogaban que se volviesen de allí y no pasase más adelante, y que le bastase y contentase con haber llegado adonde osadía ni temeridad de alguno de los mortales jamás había sido osada de pasar ni de llegar. (Transilvano, 2012: 29-30)

Todo viaje supone una construcción previa del espacio, un conjunto de expectativas que se proyectan hacia ese "allá" ignoto, pero construido en la mente del viajero como auspicioso. Frente a una realidad desoladora, el narrador reconstruye el discurso compensatorio de Magallanes donde confluyen los tópicos del padecimiento, siempre expiatorio y necesario, con el providencialismo. ${ }^{20}$

Por tanto, que les rogaba [...] que considerasen quién eran y se sufriesen un poco; y pasasen con igual corazón y esfuerzo lo que les quedaba del invierno, y que tuviesen por cierto que tanta mayor gloria y mayores galardones, premios y mercedes recibirían, cuanto con mayores trabajos descubriesen y hallasen para el Emperador, que los había enviado a aquel nuevo e incógnito mundo lleno de riquezas, de especiería y de oro. (Transilvano, 2012: 31)

Y es que el relato de viajes es también un espacio del deseo, del desengaño y de la ambición. Pero aquí lo que triunfa es el recelo, crece el descontento, el ambiente interno se transforma en amenazante, opresivo y estalla en conspiración. Las diferencias entre españoles y portugueses que menciona Anglería son reiteradas y puestas en tensión: la sospecha, el odio, la traición se tejen en los barcos y motorizan el discurso.
15. El texto, escrito en latín fue firmado en Valladolid a los pocos días del retorno de los sobrevivientes $(5$ de octubre de 1522), y estaba destinado a Mateo Lang de Wellenburg, cardenal arzobispo de Salzburgo y obispo de Cartagena. El texto lleva el siguiente título: Relación escrita por Maximiliano Transilvano de cómo y por quién y en qué tiempo fueron descubiertas y halladas las islas Molucas, donde es el propio nacimiento de la especiería, las cuales caen en la conquista y marcación de la Corona Real de España. Si bien las citas corresponden a la edición de Miraguano-Polifemo (2012), también se ha consultado la preparada por Fernández de Navarrete ( T. IV)

16. En la denominada Bibliotheca americana vetustissima de Henry Harrisse se detalla la multiplicidad de ediciones que tuvo el texto de Transilvano en países como Italia, Francia y Alemania. 17. El secretario afirma haber recabado la información de Miguel del Cano (nombre con el que se refiere al capitán) y de los marinos que "recontaron al Emperador y a muchos otros todas y cada una de las cosas en este su viaje acaecida, con tanto fe y sincera fidelidad, que según la manera de su recontamiento pareció claramente a los que las oíamos decir en toda verdad, y no ser en ello mezclados cosa alguna fabulosa" (1946: 17).

18. Ver María Jesús Benites, 2004. 19. Ver Beatriz Pastor, 1983.

20. En los estudios de Beatriz Pastor (1983) y Blanca López Mariscal (2004) se analiza en un vasto corpus el tópico del sacrificio y el esfuerzo como elementos recurrentes de los relatos de viajes. El riesgo constante es siempre superado por la intervención divina que permite al conquistador salir venturoso de los peligros. 
21. Gonzalo Fernández de Oviedo plantea las sospechosas similitudes en su Historia General de las Indias cuando señala "[...] yo he seguido la relaçión que Johan Sebastian del Cano me dió", y añade "é quasi la misma relaçión que yo sigo escribió el bien enseñado secretario de César, llamado Maximiliano Transilvano". (1852, LXX-15)

22. En contraposición, el testimonio de Ginés de Mafra, cuyo manuscrito se conserva en la Biblioteca Nacional de Madrid, fue editado por primera en 1920 por Antonio Blásquez en un volumen de la Real Sociedad Geográfica.
No hubo quien por entonces osase apelar ni de tratar del injusticia y sinrazón que Magallanes hacía de hecho contra toda razón. Pues como los castellanos viesen la sinrazón que a los suyos había sido hecha, concibieron muchos de ellos en sus pechos gran odio y malquerencia contra el capitán Magallanes, murmurando y diciendo entre sí secretamente que no había de parar aquel mal hombre portugués hasta tanto que uno a uno los matase y acabase a todos, porque quedando solo con sus pocos portugueses, se pudiese volver a su tierra con gran honra y alabanza que en Portugal le sería dada por los haber así muerto a todos (Transilvano, 2012: 33).

Transilvano, mediante un nosotros inclusivo se apropia del testimonio y se vincula así emocionalmente con esa vivencia mediatizada por el asombro y el miedo. Es tan evidente el grado de acercamiento del "nosotros" que el infalible Gonzalo Fernández de Oviedo, entre otros, afirma que en realidad el de Transilvano podría tratarse del manuscrito perdido de Elcano ${ }^{21}$ lo que supondría todo un proceso de sedimentación/plagio textual en tanto acopio interpretativo de un mismo suceso y no es ahora el momento de hablar de ese otro tipo de traición que es la que ejercen los plagiadores.

Michel de Certeau (1999) afirma que cada caminante realiza "procesos" que pueden registrarse no solo en los mapas sino en el modo en el que se trasladan al papel sus pasos y trayectorias. Actos de apropiación territorial como navegar y recorrer nutren la escritura de Ginés de Mafra, ${ }^{22}$ aunque sean muchos los años que separan el regreso del acto de escritura, da cuenta de los desplazamientos y de las percepciones del entorno. Mafra, uno de los pocos sobrevivientes de la nao Trinidad, la nave que permaneció para explorar las Molucas, dicta un texto sustancioso, rico en detalles que desnuda una realidad destructora de promesas. El marino se detiene en los enfrentamientos internos, rescata de su memoria, cohesivamente, los hechos y pone en escena a cada uno de los protagonistas.

En tiempo de los romanos los hombres que deseaban acertar con buen consejo y sin él no se movían era bueno, más ahora que siempre se pone en ejecución un negocio con quizás acertará, es mal y es cosa muy peligrosa para el que lo trae, como fue para este Cartagena y odiosa para el superior porque el Magallanes por quitar de sobre sí aquella sujeción [o sea las limitaciones para ejercer el poder absoluto], no siguiendo ninguna astucia sino muy abierta enemistad, quitó al Cartagena de su cargo de capitán; lo cual el otro sintió mucho y buscaba ocasión para procurar su venganza. (Mafra, 2012: 149)

El marino revela, como ningún otro, el modo en que Magallanes impone una violencia progresiva y sistemática que invierte el orden ideal de justicia y obediencia a la ley por un sistema degradado donde imperan las rivalidades y las intrigas. El texto es atravesado, al detenerse en la invernada, por la traición y la sospecha.

Persuadió (Cartagena) a los otros dos capitanes, conviene saber al Mendoza y al Quesada, que supiesen del Magallanes, el cual se había hecho muy absoluto y riguroso, que adónde iban, los cuales condescendidos de su ruego lo hicieron. A lo cual respondió Magallanes que siguieren su bandera y callasen. Esta respuesta oscura y desabrida, y ser el Magallanes de nación extraña, dio ocasión que aquellos capitanes de poca causa, comentando lo que ellos querían significar y como no entendiese las cosas de la mar, dijesen entre sí que Magallanes los llevaba a los portugueses (Mafra, 2012: 149).

Frente a la insatisfacción, Magallanes impone el castigo y el disciplinamiento de los cuerpos en sus formas más extremas: la tortura y la muerte. La vida social que rodea el mundo del barco se rige por un sistema de normas que tratan de asegurar la autoridad del capitán. La propia instrucción detalla los procedimientos que debían limitar e imponerse durante la travesía como si el documento proyectara, cual viaje imaginario, la presencia del rey: 
[...] vos damos poder para que á cualquier persona que en la dicha Armada fuere, que no obedecieren á lo que de nuestra parte le requirierdes é mandardes, le podáis castigar á vuestro albedrío con las penas que vos pareciere; éá los que mandardes que lo ejecuten, é no lo hicieren ni obedecieren, cayan los sobredichos en las penas que vos les pusieres, allende la cual todavía será castigado el delincuente. (Fernández de Navarrete, 1837, T. IV: 143)

El capitán intimida y amenaza: "Magallanes se receló, y mandando luego armada su nao tomo a saber de que voluntad estaba su gente, la cual halló muy fiel, como la gente española lo es; y porque para tan gran negocio, le pareció buen consejo disminuir los enemigos con sagacidad". (Mafra, 2012: 152)

El primero es Luis de Mendoza, el segundo Quesada quien, armado en la cubierta de su nao, "recibió algunas lanzas que de la gavia de la capitana le tiraban, mostrando que deseaba que le matasen" (154). Pero, como aclara Mafra dosificando, "restaba solo Juan de Cartagena" (154). La voz del marino es la menos complaciente y la única que revela la serie de castigos y las muertes que se imponen como única y concebible norma de "pacificación", oxímoron tan caro a los españoles. Magallanes, respaldado en el documento real, intenta, en un sentido inverso reinstalar la armonía de la flota:

Mandó luego hacer justicia de los dichos capitanes, a los cuales mandó hacer cuartos. A un clérigo mandó desterrar y echar en una isla por darle mayor pena viviendo, porque aquella tierra es despoblada y muy fría. Mandaba Magallanes ahorcar a cuarenta hombres de los más honrados y amigos de los capitanes muertos, y entre ellos a un hidalgo que después tuvo el mismo cargo que el Magallanes (155).

En el barco, espacio público y privado a la vez, confluyen otros espacios sociales: se traman allí las intrigas y las disidencias, es cárcel para los que se amotinan, es hospital donde curan a los enfermos, depósito de armas y bastimentos, refugio ante los ataques y también es lugar donde se ejerce la justicia: una imagen contundente es la de los cuerpos de los ahorcados colgando de las antenas de la nao. ${ }^{23}$

Dejo para el final de este apartado el "Derrotero" ${ }^{24}$ de Francisco Albo, no porque sea el más sustancioso de los cinco todo lo contrario, sino porque es el texto de los silencios. Es paradigma de lo que el Consejo de Indias considera información valiosa porque en él se consignan las lecturas de las agujas y de las observaciones celestes desde el día 29 de noviembre de 1519 hasta el 4 de septiembre de $1522 .^{25}$ El texto se construye sobre la base de estructuras fijas y repetitivas que recogen datos geográficos y astronómicos. De manera lacónica se evocan algunos detalles sobre las tierras que se recorren. Desde las costas de Brasil fue anotando, casi sin interrupciones, la situación del Sol, las distancias, longitudes y coordenadas. Hay un silencio absoluto sobre los acontecimientos centrales del viaje: los motines y la muerte de Magallanes. En el texto, sistemático y monocorde, el espacio geográfico ingresa en todas sus dimensiones técnicas, despojado de acontecimiento narrativo: "A los 13 del dicho tomé el sol en 356 grados y medio, tenía de declinación 20 grados 32 minutos, vino a ser el altura 33 grados 58 minutos, estábamos en vista de tierra en derecho del río de la Laguna, norte sur con el viento les nordeste, íbamos al oes sudueste, y el día fue martes" (Albo, 2012: 89).

La pluma es regida por un sistema de verificación que especifica, clasifica, distingue y ordena la nueva configuración del orbe, quiero pensar este texto, iluminada por la lectura de Isabel Soler, como el que traduce el movimiento del barco, de ese espacio interno y reducido, a ese externo e inabarcable que es el océano. Pese a la despersonalización de la escritura, Albo pone en escena al navegante como artífice riguroso del proceso de conocimiento de los secretos que el mar encierra. La importancia
23. Recupero una imagen del relato de Transilvano que es contundente: "Y como algunos castellanos sintiesen en esto mucha graveza, hicieron conspiración, y levantáronse contra él un capitán de la una de las naos con todos los castellanos que en ella iban y pelando Magallanes contra aquella nao con las otras cuatro, prendió el capitán y a los principales de la conspiración, y presos los ahorcó luego de hecho de las antenas de la nao sin los oír, y sin les guardar sus privilegios ni excepciones, porque siendo o, como algunos de ellos eran, oficiales del emperador no podía según derecho hacer justicia dellos, porque sólo la persona del emperador o los señores del consejo eran sus jueces, y no él." (1946: 33) 24. Se desconoce la fecha de nacimiento y muerte de Albo. Los datos indican que era natural de la isla de Aixo (cercana a Rodas). La Casa de Contratación dispuso que fuera como piloto de la nao principal Santísima Trinidad.

25. AGI, Patronato 34, Rama 5. El manuscrito, de 83 folios, también ha sido publicado bajo el título de “Diario o derrotero del viage de Magallanes desde el cabo de San Agustín en el Brasil, hasta el regreso a España de la nao Victoria" por Martín Fernández de Navarrete (1837). 
26. El 10 de septiembre de 1522 se empezaron a descargar los costales de la Vitoria. Según la documentación sumaban 381 costales en total.

27. Delle Navigationi et Viaggi está integrado por tres volúmenes que reúnen las travesías por las cuatro partes del mundo conocidas hasta ese momento: el primero contiene relatos antiguos y modernos de viajes por África e India. El volumen dos refiere los viajes por el continente asiático y fue editado de manera póstuma en 1590. Finalmente, el tercer tomo reúne los viajes por el Nuevo Mundo. El volumen dos sobre los relatos de viajes por el Nuevo Mundo reúne, entre muchos otros, las décadas de Pedro Mártir de Anglería el viaje de Pigaffeta junto con Hernando de Magallanes, la carta de Oviedo a Bembo y el Relato de Vásquez sobre la malograda expedición de Pedro de Ursúa por el Río Amazonas. del contenido del texto es clave porque al trazar y redefinir el mapa se juega todo el impacto político económico que supone encontrar una nueva ruta que no interfiera con la demarcación del Tratado de Tordesillas. De alguna manera las disputas y la violencia que, como vimos recorren las escrituras anteriores, proyectan esa línea imaginaria del tratado que divide la ambición de unos y de otros, y queda registrada en las progresivas deslealtades y traiciones de una tripulación donde la violencia es la que se impone como el único principio organizador.

\section{El Archivo: lectores y coleccionistas}

Todo viaje de exploración y descubrimiento conlleva una idea de progreso y avance, presupone un acto de apropiación y apoyo a un proyecto conquistador. Se recorre, se traza, se nombra con un objetivo y es esa búsqueda la que da sentido al viaje. Pero hay quienes participan desde la distancia de la travesía, me refiero a los lectores y, surge entonces la pregunta por el grado de impacto y circulación que tiene el corpus presentado.

Pienso estos textos, en términos de Ottmar Ette (2008), como textos traductores en tanto trasladan una experiencia individual y acotada hacia un acervo colectivo, experiencias que se recuerdan y reconstruyen, experiencias que se hacen relato visible y traducen lo visto, oído y vivido durante años de peregrinación por la ajenidad y anchura del mundo. Estas lecturas se renuevan y adquieren fines determinados de acuerdo a los momentos históricos en que se realizan. Esa condición de traducción del relato de viaje se asocia con la fascinación que conllevan esos movimientos omnipresentes en la escritura del viajero, desplazamientos entre el comprender en el espacio, entre el saber y el actuar humanos, entre lo no sabido y lo pre sabido, entre los lugares del leer y del escribir, movimientos que se condensan en la dinámica de transferir una realidad, si bien extraña, comprensible para ese lector.

La dimensión impresa a la que trascienden Pigafetta, Transilvano y Anglería hace público el descubrimiento del paso al resto de Europa. No quiero abrumar con una enumeración detallada de las múltiples ediciones de estos tres textos, solo referir que ya desde 1523 circulan copias y traducciones al italiano, al alemán al francés, en síntesis, a las lenguas de los otros imperios que pugnan por ser los dueños del mundo. Sí me interesa apuntar el dato de que ninguno de los tres textos circuló, hasta fines del siglo XIX, traducido al español. Eso no inhabilita las reiteradas escenas de lecturas que sobre estas obras reproducen el mencionado Gonzalo Fernández de Oviedo, Antonio de Herrera, entre muchos otros cronistas y viajeros.

Si bien las traducciones y reimpresiones explicitan ese interés expansionista ya que efectivamente la nao Victoria arribó a España desbordada, a falta de tripulantes, de costales con clavo de olor, nuez moscada, canela, sándalo, ${ }^{26}$ lo interesante es que el relato de viaje como tal atrae porque connota la acción de salir del mundo cerrado al universo inabarcable, porque el desafío que supone atravesar el mare tenebrosum ejemplifica el modo en que la realidad y el saber sobre un mundo nuevo se construye desde la experiencia vital de un sujeto.

Me detengo en estos tres textos y en el circuito de lectores que establecen. En 1550 son reunidos por Giovanni Ramusio en la colección de Viajes y navegaciones (publicados en Venecia entre 1550-1590). ${ }^{27}$ Los volúmenes de Ramusio son insoslayables para comprender el proceso de constitución de un nuevo lector, que empuja los límites impuestos desde la metrópolis a la escritura en y sobre América, un público lector que lee o escucha, nuevas formas de narrar sobre geografías hasta ese 
momento ignotas y que propone nuevas maneras de interpretarlas. El vínculo que cada uno de los textos establecía de manera independiente con sus lectores es ahora reorganizado y constituye una constelación centrada en el primer viaje alrededor del mundo.

El repertorio, lúcidamente trabajado por Blanca López Mariscal (2004), permite inferir tanto la construcción de remozadas tradiciones y convenciones de lectura como vislumbrar la dimensión que adquiere la figura de un editor en su afán por contener en un solo objeto-libro todos los relatos. La lectura, parece percibir el "diligente" Ramusio ${ }^{28}$ como lo define Alfonso Reyes, "es siempre una práctica encarnada en ciertos gestos, espacios y hábitos" (Cavallo y Chartier, 2011: 26) ya que su colección se ocupa de redefinir, al incorporar, de manera cronológica, un universo textual múltiple pero atravesado de manera indefectible por la experiencia del viaje. Ramusio, en tanto editor/mediador, interpela al lector ajeno a los espacios autorizados de lectura, a aquel que, apartado de la burocracia colonial, se acerca al texto movido por la curiosidad y pone a disposición de los ávidos lectores no solo un conocimiento del mundo, reconciliado con el antiguo saber, sino también les posibilita el encuentro con una experiencia, un mundo y un saber nuevos. ${ }^{29}$

La colección, y estas ideas se entraman con la lectura de Yvette Sánchez (1999), ${ }^{30}$ es también una manera de ordenar el conocimiento, conlleva un sistema de agrupación, es un repertorio que enumera e instituye el saber y que posee conexiones internas y vinculantes.

Si la lectura de un relato de viaje le permite al lector recorrer, sin fatigas, ${ }^{31}$ largas distancias, las colecciones "les ahorran a los lectores la molestia de la búsqueda y del viaje a través de las bibliotecas. En este movimiento análogo, las colecciones proponen realizar una mayor acumulación y concentración del conocimiento" (Ette, 2008: 100). La colección presupone entonces una lectura total, en tanto relato continuado y absoluto. Entonces podemos pensar que la colección es además una herramienta para recopilar y conservar un repertorio ordenado de lecturas. Esta idea de repertorio me remite a otro de los pliegues de este trabajo: el archivo. Asocio la colección con la idea de archivo en tanto espacio de conservación no cerrado, ambos, colección y archivo están en permanente construcción. En estos términos, como algo inacabado, proyectan la acción de viajar como un continuum y la de su relato como aquello que nunca se clausura.

Recopilar nunca es inofensivo afirma, con sensatez, Ottmar Ette (2008: 99) puesto que más allá del mérito de resguardar y legar para la posteridad textos que se ocupan de las novedades, posee fines políticos. Quizás no sea casual que a partir de la edición de Ramusio la Corona española reactivara nuevas exploraciones por el Estrecho de Magallanes esta vez por la boca del Pacífico ya que las que trataron de repetir la travesía magallánica fueron rotundos y onerosos fracasos. Tampoco es fortuito que ante esas reiteradas decepciones se inicie un proceso de representación lírica para clausurarlo, como modo de resguardar el secreto sobre su laberíntica y expulsora existencia:

Por falta de pilotos o encubierta

Causa quizá importante y no sabida

Esta secreta senda descubierta,

Quedó para nosotros escondida,

Ora sea yerro de la altura cierta

Ora que alguna isleta removida

Del tempestuoso mar y viento airado

Encallando en la boca la ha cerrado. (Ercilla y Zúñiga, 1949: 59)
28. Con este calificativo define Alfonso Reyes a Ramusio. La cita completa es: "El diligente Giovanni Battista Ramusio publica su peregrina recopilación Delle Navigationi et Viaggi el año de 1550 . Consta la obra de tres volúmenes in-folio, que luego fueron reimpresos aisladamente, y está ilustrada con profusión y encanto. De su utilidad no puede dudarse: los cronistas de Indias del Seiscientos (Solís al menos) leyeron todavía alguna carta de Cortés en las traducciones italianas que ella contiene. En sus estampas, finas y candorosas, según la elegancia del tiempo, se aprecia la progresiva conquista de los litorales; barcos diminutos se deslizan por una raya que cruza el mar; en pleno océano, se retuerce, como cuerno de

cazador, un monstruo marino, y en el ángulo irradia picos una fabulosa estrella náutica”. (Reyes, 1995).

29. Un ejemplo de esta afirmación son las diversas reimpresiones venecianas del tomo I de Ramusio de los años 1554, 1563, 1588, 1606 y 1613. 30. Yvette Sánchez plantea el lugar que ocupa el coleccionismo frente a las tensiones internas que se gestan dentro de esa idea: "De acuerdo con la dicotomía de la deducción y la inducción, se puede afirmar que para llegar a cualquier pensamiento y cognición discursiva es esencial coleccionar material primero y asocia sus entes (cfr. el empirismo). No falta la posición categórica opuesta (cfr. Descartes y Kant): quien se pone a coleccionar, nunca captará la verdad (empezando de cero, de la idea innata, se espera el repentino conocimiento. El tercer camino o actitud intermedia sostiene que no hay cognición sin colección, pero que la mera colección [...] no alcanza para lograr cognición. (Sánchez, 1999: 10)

31. Me detengo en el término fatiga porque es uno de los términos recurrentes en el relato de viajeros en el proceso de representación y autofiguraciones de los viajeros. La fatiga, como uno de los hipónimos del padecimiento, es tematizada en diversos relatos. Ver: Benites, María Jesús, Vigilias, fatigas y peregrinaciones": viaje, relato y desamparo en los confines del imperio". 
Para González Echevarría (2000) el archivo es la imagen del poder, el archivo guarda letra muerta, letra que dice de vidas que se fueron, cuya retención organiza y da sentido a cuerpos y documentos. La respuesta pendiente es sobre el destino de los escritos de Albo y Mafra.

Podría decir que ambos son "retenidos" por el archivo, en tanto abrumadora administración colonial. El de Albo es, como se señaló, el texto más valioso y estrictamente ceñido a la retórica de la Casa de Contratación e ingresa en un circuito burocrático de lectores casi como una privatización de la lectura. Hay registros de sus movimientos y es evidente que circularon copias o datos fragmentarios porque otros viajeros aluden a sus mediciones y trazados, en especial, a un dato clave: la distancia. Recién a mediados del siglo XIX se publica su contenido y trascendió a la letra impresa bajo el formato de ese otro archivo que son los volúmenes de Fernández de Navarrete.

El de Mafra es propiamente el texto "archivado" entendido como esa acción de clausurar, truncar toda vitalidad, transformado en esa letra muerta de la cita anterior de González Echevarría. Sobre el texto de Mafra, operan esos silencios que exploran Valeria Añón (2018) y Loreley El Jaber (2013). Aquí surge esa otra modulación que atraviesa la historia de la escritura en América Latina: la jurídica. Mafra retorna a España cinco años después que Elcano: ha deambulado por las Molucas a bordo de la nao Trinidad hasta que los 17 sobrevivientes de los 60 originales fueron apresados por los portugueses. La escritura es para él una prueba de vida, no de supervivencia o las frecuentes escrituras de servicio, y así, su texto se relee en clave jurídica porque después de años de ausencia su mujer no solo había vendido todas sus pertenencias sino que, para poder volver a casarse, había tramitado ante las autoridades que Ginés sea declarado por muerto. Nunca tan significativo el nivel de condensación de la tríada viaje-vida-muerte y sus múltiples combinaciones.

La lectura es la acción que se perfila e intuye en todo texto, no solo como una operación abstracta, sino también como una puesta en juego del cuerpo, anclada en un espacio, capaz de establecer una relación consigo misma y con los otros. Leer un viaje que se relata para otro supone acercar universos distintos y obviamente temporalidades y formas del conocimiento. Y esto se torna capital en estos relatos porque, cada uno, con sus propias concepciones de la tarea escrituraria posee clara conciencia histórica de las implicancias sociales, políticas, jurídicas y culturales que encierra todo acto de escritura.

Cierro este trabajo con una cita que da cuenta, en clave apoteótica, del impacto de la circunnavegación del mundo, si la cita inicial de Séneca, el viejo era disuasiva y clausuraba la expansión marítima, Pedro Mártir de Anglería celebra en la Dedicatoria "Al ilustrísimo Príncipe Carlos Rey Católico" que abre sus Décadas el modo en que el horizonte inabarcable se abre para esos ojos imperiales de los que habla Mary Louise Pratt (1997):

Ven, pues, ven Rey, a quien Dios tiene destinado el más alto poderío que jamás oyeron los hombres, ven y no tardes. Preparado tenemos para ti, exceptuando algo, el círculo equinoccial, desconocido hasta estos tiempos, y la zona hirviente y, en opinión de los antiguos, tostada por los ardores del sol, pobladísima de gente amena, fértil, riquísima de islas mil coronadas de oro y perlas, y en un solo que reputamos continente ofrecerte hemos tres Europas. Ven a abrazar un nuevo mundo. (Anglería, 1989. Dedicatoria: 6) 
12 Se ha discutido mucho acerca del origen del término patagón. En Historia general y natural de las Indias (1535-1557), Gonzalo Fernández de Oviedo, señala que el nombre se debe al gran tamaño de sus pies. Con esta acepción figura en el Diccionario de Autoridades: “Lo mismo que patón. Son tan altos que los españoles en su presencia parecen pigmeos, y llamáronlos patagones, por sus grandes pies". Sin embargo, según las investigaciones de María Rosa Lida, el nombre patagón proviene de un gigante que aparecía en la novela de caballerías Primaleón, publicada en 1512. No es improbable esta afirmación ya que la obra, protagonizada por Primaleón, hijo del famoso Palmerín, gozó de gran popularidad tanto en Europa como en las Indias y aparece incluso con mayor frecuencia que el Amadís de Gaula, en las listas de libros embarcados. (Ver Irwing Leonard, Los libros del conquistador, México, Fondo de Cultura Económica, 1996 y María Rosa Lida, "Para la toponimia argentina: Patagonia”, Hispanic Review, Vol. XX, 1952). Pero en el contexto americano la existencia de gigantes implicaba un apartamiento de los parámetros y límites del ser humano en tanto creación divina. Esta representación en Primer viaje... es fundante ya que adquiere tal fuerza cultural que esta mirada sobre los indígenas será recreada en las relaciones de los expedicionarios posteriores. (En página 22.) 


\section{Bibliografía}

»Albo, F. (2012). "Derrotero del viaje de Magallanes, desde el cabo de San Agustín, en el Brasil, hasta el regreso a España en la nao Victoria". En La primera vuelta al mundo. Madrid, Miraguano-Polifemo Madrid: Miraguano-Polifemo.

»Anglería, P. M. de ( 1989 ). Décadas del Nuevo Mundo. Madrid: Polifemo

»Añón, V. (2018). “El archivo y sus márgenes: cartas de mujeres en la Nueva España (siglo xvi)”. En Exlibris. Núm. 7. Pp. 6o-70.

»Añón, V. y Rufer, M. (2018). “Lo colonial como silencio, la conquista como tabú: reflexiones en tiempo presente". En Tabula Rasa, (29). Pp. 107-131.

»Benites, M. J. (2004). Con la lanza y con la pluma. La escritura de Pedro Sarmiento de Gamboa. San Miguel de Tucumán, Instituto Interdisciplinario de Estudios Latinoamericanos, Facultad de Filosofía y Letras, Universidad Nacional de Tucumán.

»Benites, M. J. (2013). “Los derroteros teóricos de una categoría heterogénea: los relatos de viajes al Nuevo Mundo (Siglo XVI)". En Moderna Sprak, Vol 107. Núm. 1. Pp. 31-38.

»Benites, M. J. (2014). "Vigilias, fatigas y peregrinaciones: viaje, relato y desamparo en los confines del imperio”. En Revista Telar, Núm. 11-12. Pp. 80-93.

»Benites, M. J. (2013). “'La mucha destemplanza de la tierra’: una aproximación al relato de Maximiliano de Transilvano sobre el descubrimiento del Estrecho de Magallanes". En OrbisTertius, 2013, XVII (19). Pp. 200-207.

»Benites, M. J. (2014). “La Patagonia: viajeros al confín de los infortunios”. En Noé Jitrik (coord.). Historia Crítica de la Literatura Argentina. Tomo I: "Una patria literaria". Cristina Iglesia y Loreley El Jaber (coords. del tomo). Buenos Aires: Emecé. Pp. 59-89.

»Benites, M. J. (2016): “Motín y traición: relatos de viaje sobre la expedición magallánica (siglo XVI)”. En María Juliana Gandini, Malena López Palmero y Carolina Martínez (Comp.). Prismas de la experiencia moderna. Europa, el mundo ultramarino y sus representaciones entre los siglos XVI-XVIII. Buenos Aires: Secretaría de Publicaciones de la Facultad de Filosofía y Letras de la Universidad de Buenos Aires. Pp. 105-120.

»Carrizo Rueda, S. (1997). Poética del relato de viaje. Kassel: Reichenberger.

»Cavallo, G. y Chartier, R. (2011). Historia de la lectura en el mundo occidental. Madrid: Taurus.

»Covarrubias Horozco, S. ([1611] 1943). Tesoro de la lengua castellana o española. Barcelona: Horta.

»De Certeau, M. (2000). La invención de lo cotidiano. México: Universidad Iberoamericana.

"Delumeau, J. (1989). El miedo en Occidente. Siglos XIV y XVIII. Madrid: Taurus.

»Duzer, Ch. van (2013). Sea Monsters on Medieval and Renaissance Maps. The British Library Publishing Division.

»Elcano, S. (2012). "Carta de Juan Sebastián de El Cano al emperador, dándole breve relación de su viaje en la armada de Magallanes y de su regreso en la nao 
Victoria“. En La primera vuelta al mundo. Madrid: Miraguano-Polifemo.

»El Jaber, L. (2013). “Archivo y relato en el Río de la Plata. El difícil discurso de la violencia”. En Orbis Tertius Nro. 19, Revista del Centro de Teoría y Crítica de la Facultad de Humanidades, Universidad Nacional de La Plata. Pp. 3-18.

"Ercilla y Zúñiga, A. de (1949). La Araucana. Madrid: Aguilar.

»Ette, O. (2008). Literatura en movimiento. Madrid: Consejo de Investigaciones Científicas.

»Fernández de Naverrete, M. (1837). Colección de los viages y descubrimientos que hicieron por mar los españoles desde el siglo XV. Tomo IV: Expediciones al Maluco - Viage de Magallanes y Elcano. Madrid: Imprenta Nacional.

" Giucci, G. (2014) Tierra del fuego: la creación del fin del mundo. Buenos Aires: Fondo de Cultura Económica.

» Glantz, M. (1992). Borrones y borradores. Reflexiones sobre el ejercicio de la escritura. México: El equilibrista.

" González Echevarría, R. (2000). Mito y archivo. Una teoría de la narrativa latinoamericana. México: Fondo de Cultura Económica.

»Gruzinski, S. (2018). El águila y el dragón. Desmesura europea y mundialización en el siglo XVI. México: Fondo de Cultura Económica.

»Irwing, L. (1996). Los libros del conquistador. México: Fondo de Cultura Económica.

"Lida, M. R. (1952). “Para la toponimia argentina: Patagonia”. En Hispanic Review, Vol. XX. Pp. 321-323.

»López de Mariscal, B. (2004). Relatos y relaciones de viaje al Nuevo Mundo en el siglo XVI. Madrid: Polifemo.

» Mafra, G. de (2012). "Relación“. En La primera vuelta al mundo. Madrid: Miraguano-Polifemo.

»Onetto, M. (2018). Historia de un pasaje-mundo. El estrecho de Magallanes en el siglo de su descubrimiento. Santiago de Chile: Centro de Investigaciones Diego Barros Arana de la Biblioteca Nacional.

»Pastor, B. (1983). El discurso narrativo de la Conquista. La Habana: Casa de las Américas.

»Pigafetta, A. (2004). Primer viaje alrededor del mundo. Buenos Aires: El elefante blanco.

"Pratt, M. L. (1997). Ojos imperiales. Literatura de viajes y transculturación. Quilmes: Universidad Nacional de Quilmes.

» Reyes, A. (1995). “Visión de Anáhuac (1519)”. En Alfonso Reyes, Obras completas. Tomo II. México: Fondo de Cultura Económica.

»Sánchez, Y. (1999). Coleccionismo y Literatura. Madrid: Cátedra.

"Séneca (2005). Controversias (Libros I-V). Madrid: Gredos.

"Séneca (2005). Controversias (Libro VI-X). Suasorias (vol.2). Madrid: Gredos.

"Sloterdijk, P. (2004). Esferas II. Globos (Macrosferología). Madrid: Siruela.

»Soler, I. (2003). El nudo y la esfera. El navegante como artífice del mundo moderno. Barcelona: El acantilado. 
»Transilvano, M. (2012). Relación escrita por Maximiliano Transilvano de cómo y por quién y en qué tiempo fueron descubiertas y halladas las islas Molucas, donde es el propio nacimiento de la especiería, las cuales caen en la conquista y marcación de la Corona Real de España. En La primera vuelta al mundo. Madrid: MiraguanoPolifemo Madrid, Miraguano-Polifemo. 